\title{
Traction test of temporary dental cements
}

\author{
Juan-Luis Román-Rodríguez ${ }^{1}$, Diego Millan-Martínez ${ }^{2}$, Antonio Fons-Font ${ }^{3}$, Rubén Agustín-Panadero ${ }^{4}$, \\ Lucía Fernández-Estevan ${ }^{5}$
}

\footnotetext{
${ }^{1}$ Doctor in Dentistry (DDS; PhD). Master Buccofacial Prosthetics (M.Sc). Associate Lecturer, Department of Dental medicine, Prosthodontic and Occlusion Teaching Unit, University of Valencia General Studies (UVGS), Spain

${ }^{2}$ Lecturer in Prosthodontics, UVGS, Spain

${ }^{3}$ Doctor in Dentistry (DDS; PhD). Assistant Lecturer, Department of Dental medicine, Prosthodontic and Occlusion Teaching Unit, UVGS, Spain

${ }^{4}$ Doctor in Dentistry (DDS; PhD). Master Buccofacial Prosthetics (M.Sc). Associate Lecturer, Department of Dental medicine, Prosthodontic and Occlusion Teaching Unit, UVGS, Spain

${ }^{5}$ Doctor in Dentistry (DDS; PhD). Master Buccofacial Prosthetics (M.Sc). Associate Lecturer, De-partment of Dental medicine, Prosthodontic and Occlusion Teaching Unit, UVGS, Spain
}

Correspondence:

Unidad de Prostodoncia y Oclusión

Departamento de Estomatologia

C/ Gascó Oliag n ${ }^{\circ} 1$ PC: 46010

Universitat de València. España

juanluis.romanrodriguez@gmail.com

Received: 17/01/2017

Accepted: 08/02/2017

Román-Rodríguez JL, Millan-Martínez D, Fons-Font A, Agustín-Panadero R, Fernández-Estevan L. Traction test of temporary dental cements. J Clin Exp Dent. 2017;9(4):e564-8.

http://www.medicinaoral.com/odo/volumenes/v9i4/jcedv9i4p564.pdf

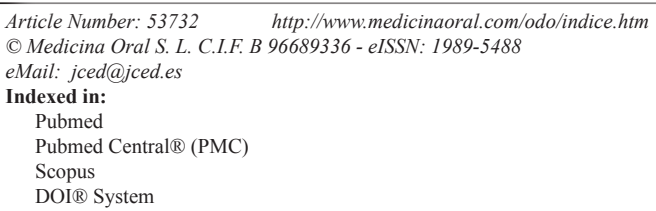

\begin{abstract}
Background: Classic self-curing temporary cements obstruct the translucence of provisional restorations. New dual-cure esthetic temporary cements need investigation and comparison with classic cements to ensure that they are equally retentive and provide adequate translucence. The objective is to analyze by means of traction testing in a in vitro study the retention of five temporary cements.

Material and Methods: Ten molars were prepared and ten provisional resin restorations were fabricated using CADCAM technology $(n=10)$. Five temporary cements were selected: self-curing temporary cements, Dycal (D), Temp Bond (TB), Temp Bond Non Eugenol (TBNE); dual-curing esthetic cements Temp Bond Clear (TBC) and Telio CS link (TE). Each sample underwent traction testing, both with thermocycling (190 cycles at 5-55 $)$ and without thermocycling.

Results: TE and TBC obtained the highest traction resistance values. Thermocycling reduced the resistance of all cements except TBC.

Conclusions: The dual-cure esthetic cements tested provided optimum outcomes for bonding provisional restorations.
\end{abstract}

Key words: Temporary dental cements, cements resistance. 


\section{Introduction}

Cementation is defined as the process of bonding a prosthetic element to a substrate with cement (1). Two types of cement are used in dentistry: definitive and temporary. The latter is used to bond a provisional prosthesis, to bond a definitive prosthesis temporarily, or to bond a prosthesis onto an implant. Both types of cement must provide adequate prosthetic retention and provide an effective seal between the post and the restoration; the seal must not suffer any changes as a result of the temperature changes in the oral cavity. It is also desirable that when a restoration is debonded, the cement stays on the restoration rather than on the tooth, as it clinically simpler and easier to remove the remaining cement extraorally.

Normally, temporary cements are classified according to their composition but they can also be classified according to their setting mechanism (1). Self-curing cements are those that consist of a base and a catalyzer, which set when they are mixed. They usually contain calcium hydroxide or zinc oxide. With dual-cure temporary cements, setting is activated by light; these are translucent resins and so considered esthetic.

1. To analyze the retention of five temporary cements by means of traction testing.

2. To assess the influence of thermocycling on temporary cements.

3 . To determine the localization of remaining cement after traction testing/debonding.

\section{Material and Methods}

This work is an in vitro study, each sample underwent traction testing, divided in thermocycling (190 cycles at $5-55^{\circ}$ ) and without thermocycling. This study has been carried out in Department of Dental Medicine. University of Valencia, Spain.

A metal model was fabricated to simulate a dental stump of standard dimensions as used in other studies (2). The stump was duplicated in plaster and then scanned using Cerec inLab ${ }^{\circledR}$ software (Sirona Dental Systems, NY, USA).

Meanwhile, ten human molars (extracted within the previous 3 months and conserved in physiological serum (3) were set in blocks of plaster shaped to fit the milling machine, which was then used to prepare the teeth following the previously scanned tooth stump model. In this way, 10 human molars were prepared exactly replicating the scanned tooth.

A coping was designed as provisional restoration, shaped to match the milled molars. The coping included a 'handle' to facilitate axial traction. Ten copings were milled from blocks of cross-linked polymethylmethacrylate (PMMA) (Telio CAD®, Ivoclar Vivadent, Schaan, Liechtenstein) for fabricating long-term provisional prostheses using CAD-CM techniques. A coping was randomly assigned to each molar.
Five temporary cements were tested, (Table 1).

All ten copings were cemented with all five cements (five study groups, $\mathrm{n}=10$ ). The five groups underwent traction testing (Instron 4804). After each test, both the molars and copings were cleaned first with a scalpel and then with a prophylaxis brush and abrasive dental paste (Détartine ${ }^{\circledR}$, Septodont, Saint-Maur-des-Fossés, France) before proceeding to the next cement. When the five groups had been tested, the traction tests were repeated first subjecting the samples to thermocycling (190 cy-

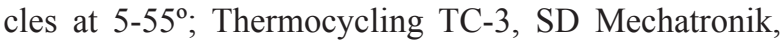
Feldkirchen-Westerham, GERMANY), equivalent to approximately 7 days, the average time that a cemented temporary restoration remains in the mouth.

Statistical analysis was performed using SPSS-Windows ${ }^{\circledR}$ software (Statistical Package for the Social Sciences. SPSS Inc. Chicago, Illinois, USA), importing data from a single Microsoft ${ }^{\circ}$ Excel spreadsheet. Descriptive and bivariate analyses were performed, applying the Pearson $\chi^{2}$, Kruskal-Wallis and Mann-Whitney. The significance level established for all bivariate analysis was $1 \%$, any $p$-value below 0.01 indicating a statistically significant difference.

\section{Results}

Temp Bond NE and Telio CS Link obtained the best initial retention values. After thermocycling, the retention values of all cements were seen to decrease, with the single exception of Temp Bond Clear. After thermocycling, Telio CS Link obtained the best retention, followed by Temp Bond Clear, (Fig. 1).

When the cements were grouped according to setting mechanisms, dual-cure cements presented the highest resistance values after thermocycling compared with classic self-curing cements, (Fig. 2).

For dual-cure cements, the cement remaining after debonding was found on the restoration, while self-curing cements always remained on the tooth, (Fig. 3).

\section{Discussion}

Few studies have investigated the retention of temporary cements, and the bibliography that does exist is scant, heterogeneous, and disparate. Each study uses a different methodology, particularly regarding the preparation of specimens, and while they provide an overview of general tendencies, it remains impossible to make a precise comparison of the results $(4,5)$. The authors believe that the preparation method used in the present study proved both innovative and efficient, as it produced teeth of identical dimensions by means of reproducible CAD- CAM technology. This method will be the subject of a further article.

The results confirmed the considerable influence of thermocycling on retention values in all cases with a single exception - Temp Bond Clear. After thermocycling, the dual-cure cements obtained higher retention values, 
Table 1: Cements tested in the study.

\begin{tabular}{|c|c|c|c|c|}
\hline Name & Manufacturer & Main composition & Setting type & Lot number \\
\hline Dycal (D) & $\begin{array}{l}\text { Dentsply Caulk, } \\
\text { Delaware, USA }\end{array}$ & $\begin{array}{c}\text { Base } \\
\text { 1,3-butylene glycol disalicylate, Zinc oxide, } \\
\text { Calcium phosphate, Calcium tungstate, } \\
\text { Iron oxide pigments. } \\
\text { Catalyzer } \\
\text { Calcium hydroxide, N-ethyl-4-toluene } \\
\text { sulfonamide, Zinc oxide, Titanium dioxide, } \\
\text { Zinc Stearate, Iron oxide pigments (only } \\
\text { dentin color). }\end{array}$ & Self-curing & $105202014-0$ \\
\hline Temp Bond (TB) & $\begin{array}{c}\text { Kerr S.r.l. } \\
\text { Scafati, Italia }\end{array}$ & $\begin{array}{c}\text { Base } \\
\text { Zinc oxide (ZnO) } \\
\text { Catalyzer } \\
\text { Zinc acetate dihydrate, Rosin, oligomers } \\
\text { (NLP) and eugenol. }\end{array}$ & Self-curing & 5275048 \\
\hline $\begin{array}{l}\text { Temp Bond NE } \\
\text { (TBNE) }\end{array}$ & $\begin{array}{c}\text { Kerr S.r.l. } \\
\text { Scafati, Italia }\end{array}$ & $\begin{array}{c}\text { Base } \\
\text { Zinc oxide (ZnO) } \\
\text { Catalyzer } \\
\text { (R)-p-mentha-3,8(9)-diene, Zinc acetate } \\
\text { dihydrate, Rosin, oligomers (NLP). }\end{array}$ & Self-curing & 5275031 \\
\hline $\begin{array}{l}\text { Temp Bond Clear } \\
\text { (TBC) }\end{array}$ & $\begin{array}{c}\text { Kerr S.r.l. } \\
\text { Scafati, Italia }\end{array}$ & $\begin{array}{c}\text { Base } \\
\begin{array}{c}\text { Unpolymerized urethane-acrylate } \\
\text { monomers }\end{array} \\
\text { Catalyzer } \\
\text { Unpolymerized urethane-acrylate } \\
\text { monomers, Dibutyl phthalate. }\end{array}$ & Dual-cure & 5275065 \\
\hline $\begin{array}{l}\text { Telio CS Link } \\
\text { (TE) }\end{array}$ & $\begin{array}{c}\text { Ivoclar } \\
\text { Vivadent AG, } \\
\text { Schaan, } \\
\text { Liechtenstein }\end{array}$ & $\begin{array}{c}\text { Base } \\
\text { Polyethylene glycol dimethacrylate } \\
\text { Catalyzer } \\
\text { Polyethylene glycol dimethacrylate, } \\
\text { benzoyl peroxide, stabilizers and pigments. }\end{array}$ & Dual-cure & U246680-2017-06 \\
\hline
\end{tabular}

which shows that these cements are indicated in cases with short or convergent tooth stumps, when restoration retention may be compromised (1). The present results coincide with data obtained by Lawson in a study of self-curing and dual-cure cements that included thermocycling (1). Dual-cure cements are indicated for anterior teeth whenever the definitive restoration involves partial or complete coverage because of their translucency, retention capacity, and the fact that there is no eugenol in their composition. Non-eugenol cements will not compromise adhesion providing the definitive cementation is carried out with composite resins $(6,7)$. Self-curing cements are indicated both in the posterior sector, in the anterior sector when it is to be restored with metal-ce- ramic restorations; in these cases cements with eugenol can be used as adhesive cementation of the definitive prosthesis is not a requirement (7).

Lepe et al. (8) did not find differences between Dycal, Temp Bond and Temp Bond NE, while Fernandes et al. found that Dycal achieved better retention, as in the present study (9). Rego et al. (10) obtained lower retention with Temp Bond NE, as did the present study.

It is important to bear in mind that if the immediate dentin sealing technique (IDS) is to be used, then it is recommended that dual-cure cements be avoided, as the tooth stump is protected with a resin after preparation and there will be a risk of union between the resin and the temporary cement $(11,12)$. 


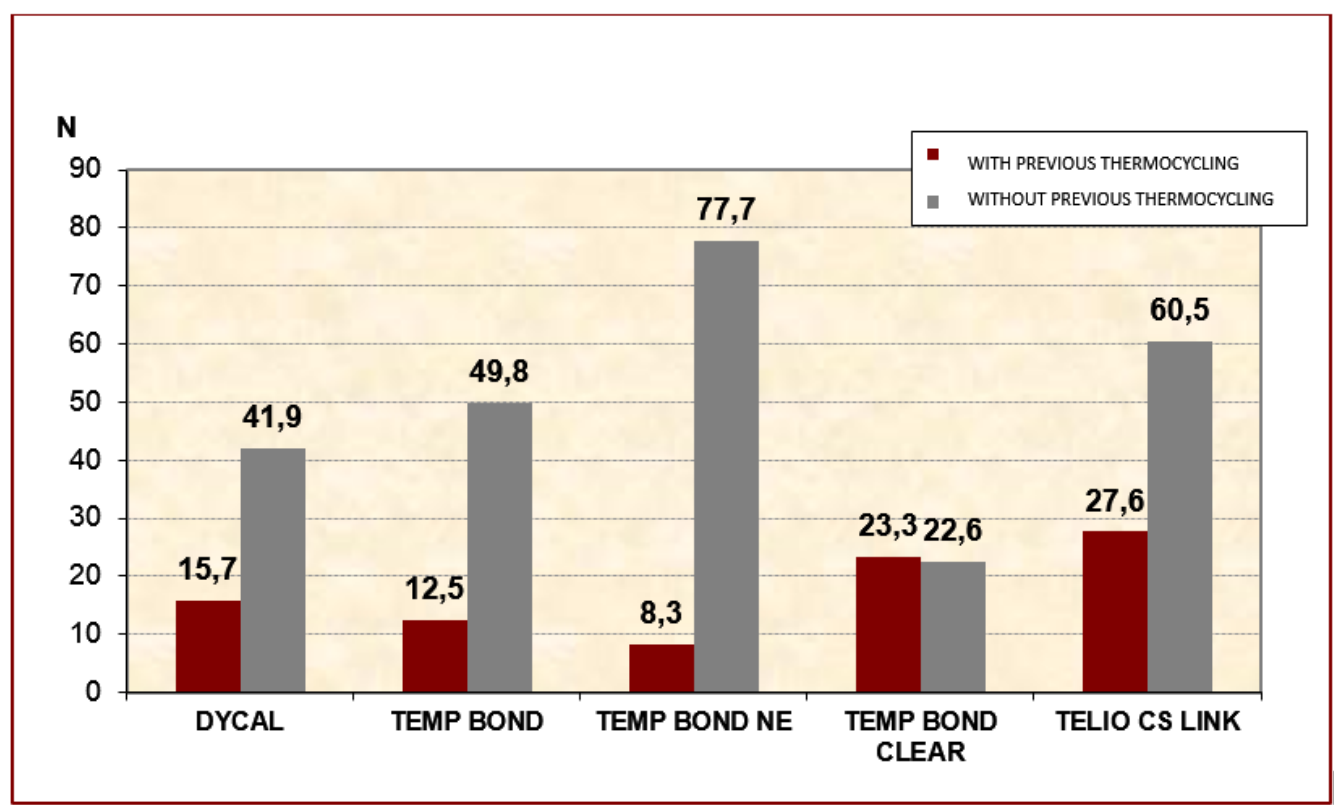

Fig. 1: Mean resistance values for each cement, with or without thermocycling.

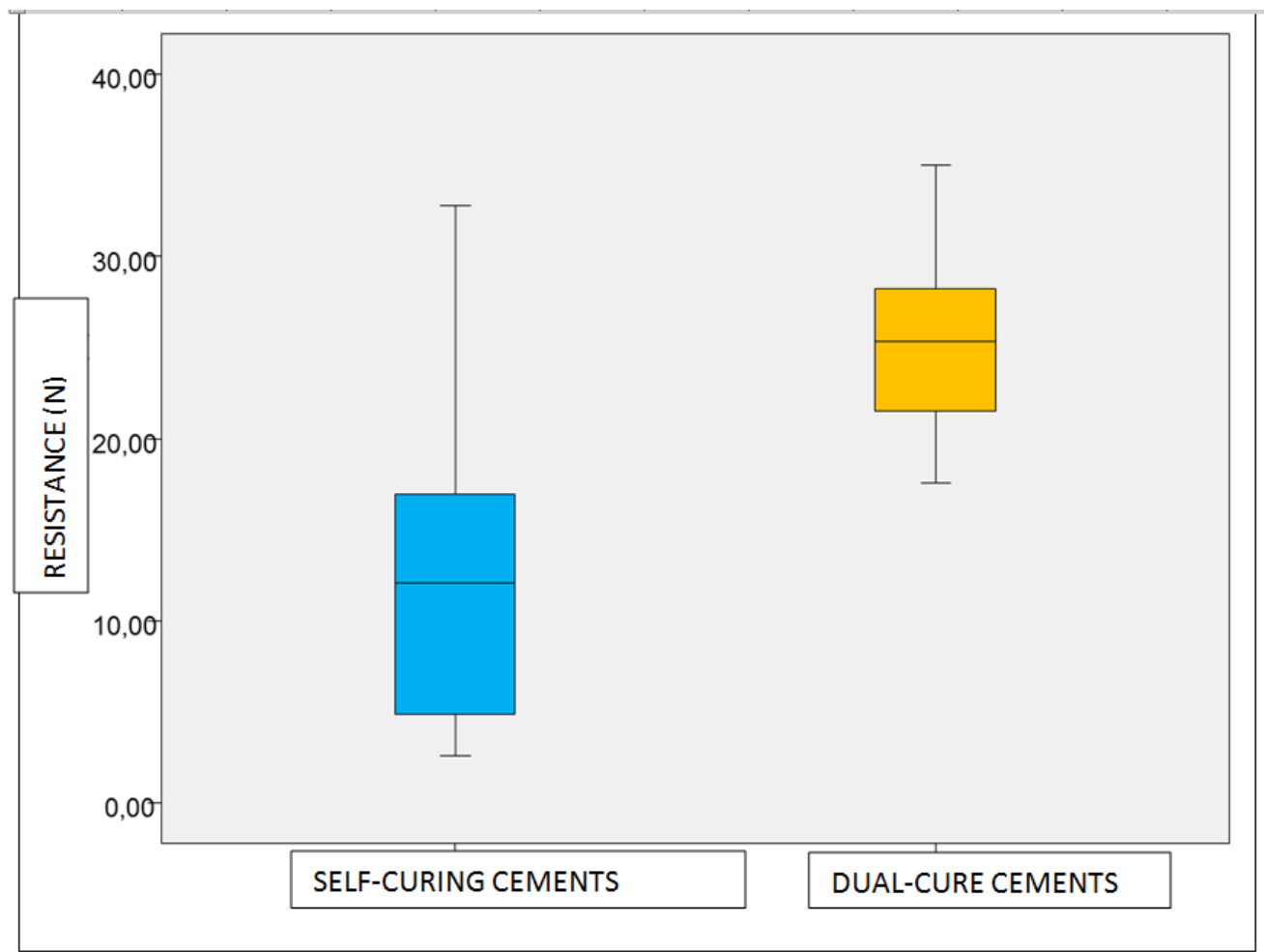

Fig. 2: Box-plot of traction resistance after thermocycling for both types of temporary cements.

The localization of temporary cement after debonding showed differences between the two types of cement, with more cement remaining on the restoration when dual-cure cements were used. It is better for cement to remain on the prosthesis rather than the tooth, as it can be cleaned extraorally, which saves inconvenience for the patient and avoids obliterating the dentinal tubules. Within the limitations of this in vitro study, it may be concluded that:

1. Temporary dual-cure cements (Telio CS Link $>$ Temp 


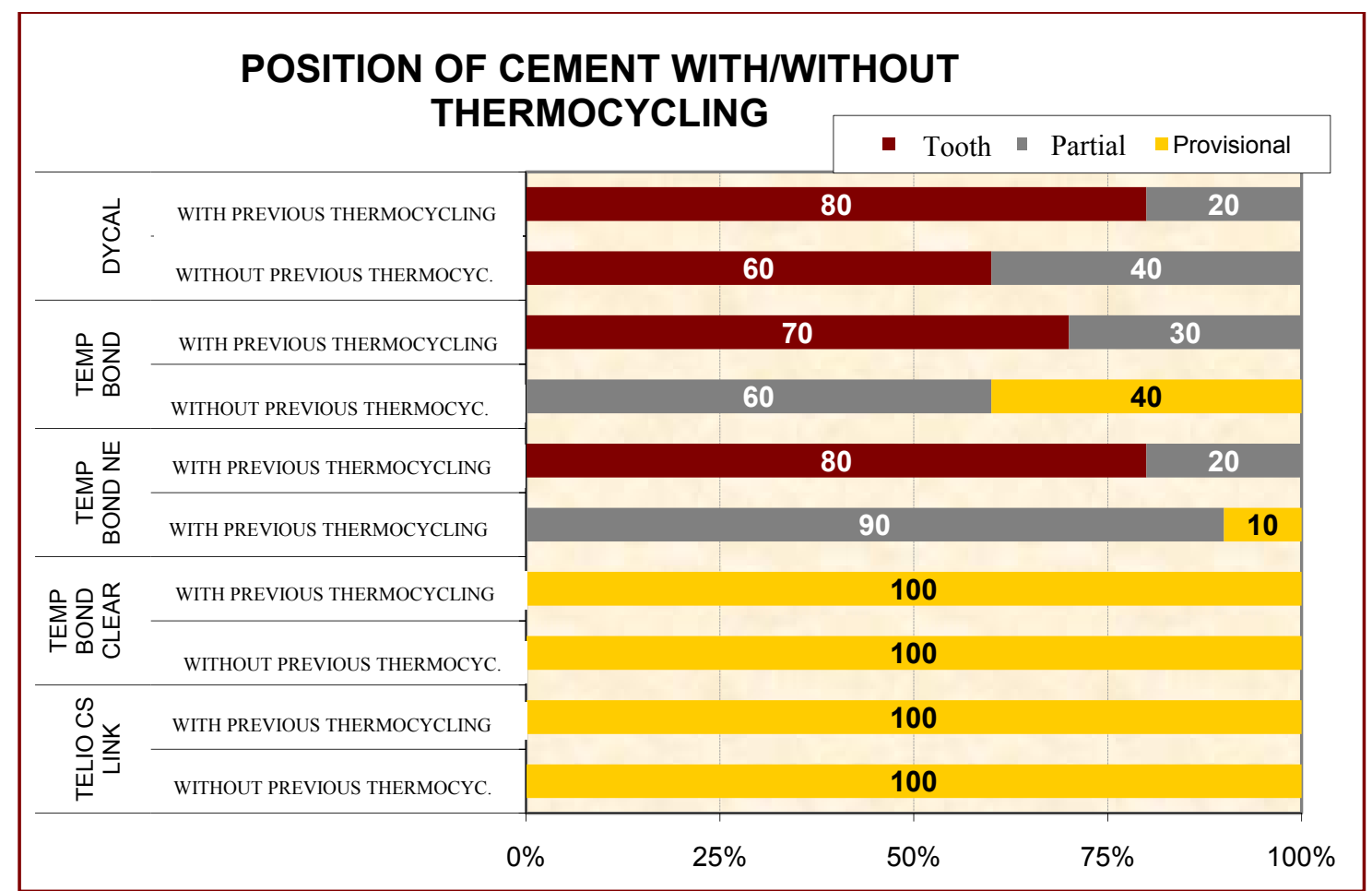

Fig. 3: Localization of cement remains (on either restoration, tooth, or both [partial]) after debonding deriving from traction testing.

Bond Clear) obtain better retention than self-curing cements.

2. Thermocycling reduces retention of all the cements tested, with the exception of TBC.

3. After debonding, dual-cure cements remain on the restoration, while self-curing cements remain on the teeth.

\section{References}

1. Lawson NC, Burgess JO Mercante D. Crown retention and flexural strength of eight provisional cements. J Prosthet Dent. 2007;98:455-60. 2. Suarez MJ, Gonzalez de Villaumbrosia P, Pradies G, Lozano JF. Comparison of the marginal fit of Procera AllCeram crowns with two finish lines. Int J Prosthodont. 2003;16:229-32.

3. Palacios RP, Johnson GH, Phillips KM, Raigrodski AJ. Retention of zirconium oxide ceramic crowns with three types of cement. J Prosthet Dent. 2006; 96:104-14.

4. Perdigao J. Dentin bonding- Variables related to the clinical situation and the substrate treatment. Dent Mater. 2010;26:e24-e37.

5. Sachin B. Comparison of retention of provisionals crowns cemented with temporary cements containing stannous fluoride and sodium fluoride - An in vitro study. J Indian Prosthodont Soc. 2013;13:541-5.

6. Lewistein I, Stoleru-Balon J, Block J, KfiR A, Matalon S, Ormianer Z. Antibacterial activity and tensile strength of provisional cements modified with fluoride-containing varnish. Quintessence Int. 2013;44:107-12.

7. Ribeiro J, Coelho P, Janal M, Silva N, Monteiro A, Fernandes C. The influence of temporary cements on dental adhesive systems for luting cementation. Journal of Dentistry. 2011;39:255-62.

8. Lepe X, J. Bales D, H. Johnson G. Retention of provisional crowns fabricated from two mate-rials with the use of four temporary cements. J Prosthet Dent. 1999;81:469-75.

9. Fernandes PFS, Vide PAFB, Almeida TC, Amaral TD, Silva CL, Ferrandes JCAS. Retencao de Cimentos Provisorios em Dentes Naturais para Próteses Fixas Unitárias. Rev Port Estomatol Cir Maxilofac. 2007;48:215-19.
10. Rego MRdM, Santiago LC. Retention of provisional crowns cemented with eight temporary cements. Comparative study. J Appl Oral Sci. 2004;12:209-12.

11. Magne P, Kim TH, Cas D, Donovan T.E. Inmediate dentin sealing improves bond strength of indirect restorations. J Prosthet Dent. 2005;94:511-9.

12. Palacios RP, Johnson GH, Phillips KM, Raigrodski AJ. Retention of zirconium oxide ceramic crowns with three types of cement. J Prosthet Dent. 2006;96:104-14.

\section{Conflict of Interest}

The authors have declared that no conflict of interest exist. 